\title{
Executable Urbanisms: \\ Messing with Ubicomp's Singular Future
}

Marc Tuters ANd Michiel de LANGe

\section{INTRODUCTION}

This chapter consists of two parts. In the first part we take a brief look at how locative media coincide with a >Spatial Turn in media studies. In the last decades of the twentieth century the notion of a sthird waver of human-computer interaction technology from corporate research and development projects into the mainstream media. According to the technology discourse, information would soon become context-aware, acquiring something like its own sbody with which we might interact against the backdrop of architectonic space. We would thus move from the graphic user interface as desktop, to new metaphors of rooms, streets, cities and even the planet as a whole. While the concept of a mobile spatial interface has today become commonplace due to the integration of location-sensing technology into smartphones in the latter part of the first decade of the twenty-first century, we argue for a new consideration of this 'Spatial Turn through discussions in cultural geography as well as by practices in media art drawing on the metaphors of second nature, spatial practice, cognitive mapping, and traceability. In seeking to address the social impact of this rapid technological change we look towards a community of practice that has, for the past decade, explored alternate socio-technical arrangements of space 
and mobility, and to the conversations it has generated. We argue that these projects reference a deeper tradition of critique as developed primarily by cultural geography. In the second part of this article we focus specifically on how the practice of locative media has sought to engage with some of the aforementioned concepts, and how in turn it might illuminate some of the blind spots in ubiquitous computing (ubicomp) research, as identified in the recent critical work of Dourish and Bell (2011). We pay specific attention to their notions of legibility (how people read places, technologies and actions), literacy (how information is represented), and legitimacy (attention for culturally variable forms of senvironmental epistemologies $`$ ) in dialogue with which we generate the concept of »executable urbanism«.

\section{New Media Geography}

The social science and humanities literature on Information and Communication Technologies (ICTs) has long considered these technologies as essentially splacelessı and transcendent in regards to both space and time. Over the past decades, cultural geographers and media theorists alike have portrayed the impact of ICTs as weakening or even obliterating the need for spatial concentration in cities and location in general (for critical discussions, see: Downey/ McGuigan 1999; Graham 2004), as well as the locale of social relations and identities based on proximate face-to-face interaction (Meyrowitz 1985: 308). Some authors have captured this new media sparadigm ‘ with the phrase "anyplace, anytime, anywhere (Graham 2004: 4; Kuitenbrouwer 2006: 56). Counterbalancing the emphasis on abstract networks, recent scholarship from fields of media studies and human computer interaction $(\mathrm{HCI})$ have focused on how the personal use of mobile devices may contribute to »a sense of place« (Nyíri 2005). From the hardware backbone of national Webs, in which routers trace the geographical origins of packets (as in the case of the Great Firewall of China), to the physical entry points going mobile and hence becoming traceable (iPhones, Droids, etc), to the rise of local content (Google maps, Yelp, etc.), geography has reasserted itself online (Goldsmith/Wu 2006) in what some web epistemologists have referred to as "geo-locative« research (Rogers 2009).

Inversely, geography has had to deal with the spatial reconfigurations brought about by ICTs. This is most evident in urban studies. Since the mid1990s urban theory has increasingly focused on grounding media in urban space, whether in terms of analyzing infrastructures (Castells/Hall 1994), sociologically in the form of neighborhood websites (Hampton/Wellman 1999), anthropologically in terms of cultural variations in web usage (Miller/Slater 2000), or pragmatically in terms of urban design implications (McCullough 2004). Rather than being framed in terms of substitution, urban life and media technologies are increasingly seen to mutually modify one another (Graham 2004: 9; De Lange 2010: 161-163). The analysis of such complex relationships has, in turn, called for the development of new transdisciplinary research agendas for which a proliferation of terms abound: »the city of bits (Mitchell 1995), "the computable city « (Batty 1995), »the real-time city « (Townsend 2000), »the cybercity (Graham 2004), "the augmented city « (Aurigi/De Cindio 2008), »the sentient city " (Crang/Graham 2007; Shepard 2011), »urban informatics « (Foth 2009), »urban computing« (Greenfield/Shepard 2007), "the hybrid city“ (De Lange/De Waal 2009), and indeed »locative media“ (Tuters/Varnelis 2006).

While mobile media technologies are considered part of a broader class of ICTs, they have from the outset nevertheless been conceptualized as distinctive from computers and the Internet because of their relation to the urban milieu (De Lange 2010: 138). Mizuko Ito, for instance, notes that mobile communications studies have "foregrounded sociocultural diversity in a way that was not, at least initially, evident in Internet studies ( (Ito et al. 2005: 5). Mobile communication studies emphasize how the mobile phone integrates online and physical worlds, colonizing and adapting to the structures of existing practices and places, thus moving computing away from the desktop and into everyday settings (ibid.: 13). From a technological point of view, a large number of current mobile gadgets have become natively equipped with location-based capabilities - initially through satellite-based global positioning, increasingly through more localized systems from wireless access points to camera-readable markers and eventually by ubiquitous radio frequency connectivity with manufactured objects. ${ }^{1}$ Over the course of the past decade, a multitude of prototypes have been developed for envisioning this mobile location-aware future, connecting the

1 GPS uses satellite signals to establish a receiver's absolute geographical position with fair accuracy (up to $30 \mathrm{~cm}$ accurate under good conditions). Internet users have IP numbers that reveal someone's physical location with surprising accuracy. Other technologies like Bluetooth, NFC (near field communication) based on RFID, and WiFi, denend on the relative position (or proximity) of a device to another device or the depend on the relative position (or proximity) of a device to anther network. Many recent smartphones house an accelerometer, a compass, and a proximity sensor, to measure how the device is being held, to which direction it points, and whether it is near to another object. 
seemingly divergent fields of the media arts, interaction design, and corporate and university-based R\&D. For sake of clarity, we will use locative mediar to refer to the media arts, and slocativer or sgeo-locatives to refer to network technologies and practices that connect digital information and communication to splace $\iota^{2}$ New media artists are often the first to explore the limits of converging media. Locative media would thus emerge as an artistic practice shortly after the US military opened up GPS for civilian purposes in the early part of the last decade, nearly a decade before such technology became embedded within consumer mobile devices. Exploring digital cartography through mobile devices, locative artists developed new notions of spatiality. Establishing itself as a media art genre, locative media has subsequently been framed as being part of a "spatial turn « in media and cultural studies (Thielmann 2010). As a means by which to discuss this "spatial turn«, we wish to therefore begin by considering locative media in the context of urban studies and (mobile) ICT research, even though the term itself referred originally to a community of practice in the media arts.

\section{Second Nature}

Early-modern urban theorists considered media and urbanism as complementary realms. In the famed essay The Work of Art in the Age of Mechanical Reproduction, so often cited by both media scholars and urbanists, Walter Benjamin ([1936] 2008: 37) stated:

"Our bars and city streets, our offices and furnished rooms, our railroad stations and our factories, seemed to close relentlessly around us. Then came film and exploded this prison-world with the dynamite of the split second, so that now we can set off calmly on journeys of adventure among its far-flung debris.»

Ironically, Benjamin's sensitivity for mediated experiences of urban life led successors to develop a deterministic hypothesis of media's substitution effects on urban space, and the familiar Situationist critique of the media spectacle that

2 John Agnew distinguishes three elements of place: (1) Location: a specific position or area. This is geographical metric place. (2) Locale: the material setting in which social relations are constituted. This social meaning of place can also be called social situation. (3) Sense of place: the local "structure of feeling «. This is the subjective and emotional experience people have of place (Agnew 1987: 28). overwhelm authentic urban experience (Debord 1955). In this so-called substitution scenario time and space transcending technologies would obsolete the necessity to live in dense urban concentrations (Graham 2004: 9). In contemplating the image of his "Global Village«, McLuhan for instance imagined that "the very nature of city as a form of major dimensions must inevitably dissolve like a fading shot in a movie " (McLuhan, 1994: 366). The idea of the city losing ground to electronic media reaches its apex in Virilio's critique on realtime »telematics« $(1991: 14)$ :

"As a unity of place without any unity of time, the City has disappeared into the heterogeneity of that regime comprised of the temporality of advanced technologies. The urban figure is no longer designated by a dividing line that separates here from there. Instead it has become a computerized timetable."

For Virilio this signified "a global delocalization of human activity « (1997: 82) and the consequent »death of geography« (ibid.: 65).

The idea of a technological layer substituting a more fundamental reality is best understood as emerging from the tradition of cultural Marxism, particularly Lukacs' concept of "second nature" as developed by Benjamin in the above quoted essay. While capitalism rappeared c to Marx as an immense accumulation of commodities, through the work of philosophy, one could however reveal its base and transform its superstructure. This hermeneutical approach instilled a suspicion of vision in later subsequent postmodern theory, particularly in France, in which the mevil eye emerged from the realm of superstition to become the ruling metaphor of social control and political oppression at its most insidious « (Jay 1994: 378). In the nineties, a postmodernist school of cultural geography developed a critique of urban space as a social product as opposed to its appearance as a kind of scontainer (for social processes, a key foundational figure for which discourse was the French Marxist geographer Henri Lefebvre. Like his famous disciple, Jean Baudrillard, Lefebvre was suspicious of images produced by capitalism, which he considered to transport the body into an abstract visual regime (Dimendberg 1998) 


\section{Spatial Practise}

Henri Lefebvre was a crucial figure in the cultural turn of Marxism towards the "critique of everyday life« as the site of hegemonic ideology, and a materialist analysis of uneven processes in the "production of space«. Indeed, for Lefebvre, the relationship of space to social movements was key to understanding capitalism. His emancipatory politics sought to free sspatial practices from the tyranny of "dominant modes of spatial production « which encode power dynamics into the built environment. In Lefebvre's critique, architecture, for instance, was an inherently compromised profession for its close relationship to capital. Likewise, he criticized geography, from within a Marxist telos, for reifying space; by contrast, Lefebvre saw space as a product of social encounter (Gottdiener 1994). For Lefebvre, social movements produce their own integral fluid spaces, which, if realized, amount to revolution, however, the dominant power's $>$ representations of spacer marginalize and fracture these social wholes into abstract cellular arrangement. To resolve this situation, Lefebvre proposed that city dwellers become the conscious sproducers of liberated spaces, in what geographer Neil Smith characterizes as a mjumping scale model of liberation from body to interpersonal space; from the liberation of a park to the scale of the neighbourhood; from the neighbourhood to the city; the city to the nation and so forth " $(1998: 66){ }^{3}$ This approach to the analysis of space became extremely influential on a strain of cultural geography, as represented in Fredric Jameson's famous formulation of postmodern hyperspace (Dear 2000: 47-69).

In Postmodernism, or, Cultural Logic of Late Capitalism (1991), a foundational article on postmodernism in Anglo-American cultural studies, Jameson developed a variant on the substitution hypothesis` when contemplating the subject's ability to position itself in relation to an externally mappable reality. Jameson's famed argument posited the emergence of architecture as a cultura dominant concurrent with a historical period (which he referred to as mlate capitalism «), arguing that as culture accelerated and became harder to decode, it was architecture that was "closest constitutively to the economic, with which, in the form of commissions and land values, it has a virtually unmediated relationship« (ibid.: 240). Jameson's theory stemmed from a reading of what he

3 Recent social movement studies have built on these radical cartographic conception of space, particularly in work on geographies of resistance, global justice movements, and anti-nuclear movements (see Cobarrubias/Pickles 2009: 37). called the "hyperspace of the Bonaventure hotel in Los Angeles in which he claimed $n[t]$ here has been a mutation in the object, unaccompanied as yet by an equivalent mutation in the subject« (ibid.: 240). Designed by John Portman, the Bonaventure was constructed between 1974 and 1976 on Bunker Hill in downtown L.A. - the site of a former residential neighborhood destroyed as a part of a controversial slum clearance scheme in the 1950's (Davis 1992). The design of the hotel was unique at the time in that it kept visitors from directly accessing its urban surroundings. Jameson experienced this "postmodern hyperspace as both disorientating and disconnected from its urban context. For Jameson, the space of the Bonaventure did mnot want to be a part of the city but rather its equivalent and replacement or substitute « (1991: 40). Influenced by Jameson, the substitution critique thus developed a narrative of loss over the perceived dismantling, and ensuing sthemed reconstruction, of the public realm by corporate interests (Sorkin 1992; Zukin 1993). Virilio would apply this critique to the emerging field of augmented reality technology stating, none can't even know what it means to be lost in reality... « thus "(w)e are far away from simulation, we have reached substitution « (Virilio, cited in Wilson 1994: n.p.). Jameson seems to share Virilio's resignation in his analysis (1991: 46):

"This latest mutation in space - postmodern hyperspace - has finally succeeded in tran scending the capacities of the individual human body to locate itself, to organize its immediate surroundings perceptually and cognitively to map its position in a mappable external world. It may now be suggested that this alarming disjunction point between the body and its built environment... can itself stand as the symbol and analogon of that even sharper dilemma which is the incapacity of our minds, at least at present, to map the great global multinational and decentered communicational network in which we find ourselves caught as individual subjects.

\section{Cognitive Mapping}

In contrast to Virilio, Jameson's project leaves a space open for the revolutionary spatial practice theorized by Henri Lefebvre through his reference to the concept of the scognitive map c - a notion which would become central in framing locative practice (Tuters/Varnelis 2006: 351). While this concept has in turn been developed by new media theory (Holmes 2004), Jameson borrowed the notion from empirical research conducted by the American urban planner Kevin Lynch in the late fifties, in which Lynch asked what a city's form actually 
meant to the people who lived there and what the planner could do to make urban space more habitable (Lynch 1960). Based on a five-year study in three disparate cities (Boston, Jersey City, and Los Angeles), Lynch had participants trace-out their own personal mental images of the city. He then analyzed this data in order to produce diagrams of the city in terms of collective use and perception represented in abstract elements such as paths, edges, districts, nodes, and landmarks. In addition to developing an evocative metaphor through which new media theory can converse with both psychology and cartography, Lynch's work also pioneered a qualitative research method and sought to create a normative design typology, paving the way for what today would be referred to as susability c centered research (a topic to which we will return below).

The postmodern school of geography, upon which Lefebvre and Jameson both have been a noted influence (Dear 2000, 47-69), had its roots in a Marxist tradition of attempting to connect the fetishized superstructural objects with an alienated labor base. From this perspective, the role envisioned for the cognitive map is to unveil a false realm of appearances, in order to expose the truth of exploited industrial relations below. Paradoxically, the style of architectural postmodernism to which Jameson was responding was itself characterized by an embrace of all things ssuperstructurak (vernacular style, pop culture aesthetics, etc.), and a corresponding near abandonment of any modernist pretense to address social problems at the sbasec. We see this same pattern repeating itself today with a current wave of architectural practices again giving up much of the oppositional discourse that had characterized earlier avant-gardes (Hayles/Gannon 2012). Ironically this postmodern embrace of capital can be seen as a reaction to a more pessimistic Marxist critique by Italian architecture historian Manfredo Tafuri, which diagnosed the ambitions of modern architecture for social change as being beyond the scope of the discipline (1979). Tafuri argued that the varieties of design practice and their rationalizations are varieties of ideology within the overarching domination of capitalism as a system for allocating land, capital, bodies, and ideologies. In contrast to cultural Marxism's predominant pessimism, Jameson's notion of the cognitive map has functioned as the basis for a renewed interest in the emancipatory possibilities of spatial practice in the context of new media. Brian Holmes, for instance, seeks to deepen Jameson's global cognitive mapping project through engaging poststructuralism in Deleuze's work on Foucault where a map is "a cartography coextensive with the whole social field « (Deleuze 1988: 34 ). An outspoken proponent of activist media art, Holmes has collaborated, for instance, with the
Bureau d'Études in an attempt to render the global economy visible by producing mapping visualizations. In reaction to the resignation of the postmodern period, this perspective is representative of a shift towards a greater engagement with practice as well as a mode of critique, associated with the rise of Deleuzoguattarians in the European media arts milieu (see: Barbrook 2007). The discourse around locative media thus emerged within this politicized context of the media arts, in which cartography was conceived of as the new frontier of tactical media (see: Tuters/Smite 2004).

Locative media can be seen as having developed prototypes for Jameson's cognitive map by quite literally tracing the social. This has not, however, been an unproblematic proposition. Indeed, the basis for this quantification is critiqued as relying on the more-or-less wholesale implementation of a calculative infrastructure throughout every level of urban existence for which Nigel Thrift (2008) has proposed the term "qualculative«. Thus, in so far as locative media's proposition was greeted as original by the media arts community, it has paradoxically been in terms of an avant-garde of the Foucauldian/Deleuzian ssociety of control (Tuters/Varnelis 2006: 360). As Latour reminds us, while every entity, whether human or not, produces traces, a social theory is only as good as its statistics (November et al. 2010). Once digital technologies make it possible to quantify these traces, a locale becomes endowed with a multitude of voices that can less easily be ignored (Mitew 2008). In the remainder of this chapter, we discuss how the practices of locative media and the spatial and mapping metaphors upon which they are often based, might inform today's dominant discourse on ubiquitous computing.

\section{LEGIBILITY, LITERAY \& LEGITIMACY: LEARNING FROM LOCATIVE}

As famously proposed by Xerox Parc researcher Mark Weiser, ubiquitous computing refers to a future vision in which computing technologies would be a constant background presence, used to overcome the modern problem of information overload. Weiser's vision initiated the ubicomp paradigm in computing, which he called the third great paradigm after the mainframe and personal computer. This was an influential research agenda in Human Computer Interaction $(\mathrm{HCl})$ research throughout the 1990 s, which sought to develop contextaware applications and so-called »natural interfaces" (Dourish/Bell 2011: 16). 
While these projects tended to focus on embedding computing systems in a lab setting, computer scientist and $\mathrm{HCl}$ theorist Paul Dourish noted that by 2001 the use of mobile phones was in fact beginning to realize Weiser's vision in the wild (Moran/Dourish 2001: 88). By 2006 he claimed that ubicomp was, in effect, already shere and now , albeit in a different shape (Bell/Dourish 2006). In Divining a Digital Future: Mess and Mythology in Ubiquitous Computing (2011), Dourish and Bell look back at two decades of ubicomp research, revisit its well-known claims and formulate three critical issues (Dourish/Bell 2011: 22). First, ubicomp's emphasis on the sproximate future keeps placing achievements out of reach while ignoring that the future is already here (ibid.: 25). Second, combined with a narrow focus on engineering challenges the emphasis on a proximate future continually out of reach absolves ubicomp researchers from looking at complex and varying socio-cultural settings and practices. So, even if ubicomp researchers look at cultural context, they tend to treat ethnography merely as a way to deliver vivid case material and simplications for design ( (ibid.: 65). Third, the envisioned singularity of a seamless ubicomp future is a powerful myth that ignores the messiness of everyday life. Frequently, "cultural and social practices privilege disconnection, seams, and discrete distinct realms of activity and action « (ibid.: 22)

Dourish and Bell propose that ubicomp research uses ethnography's theory and methodology. By putting on a scultural lens, they show how infrastructures, mobility, privacy and the domestic realm are indeed far messier than the ideal of homogeneous and orderly spheres that can be catered for by seamless, calm technologies. In their discussion of mobility, for instance, they say:

"Our sense of spatial organization emerges from the patterns of movement of everyday life, as made visible in Kevin Lynch's study (1960) of people's segological maps of their cities. [...] Mobile technology is not, then, simply operating within a specific environment; it is implicated in the production of spatiality and spatial experience« (ibid.: 120).

This plea for a cultural view in ubicomp is a clear break with seeing space as a Cartesian container.

Dourish and Bell propose three orientations for future ubicomp inquiries: »legibility « (how people read places, technologies and actions), »literacy « (how information is represented), and »legitimacy « (attention for culturally variable forms of senvironmental epistemologies`) (ibid.: 192-200). It strikes us that these are precisely the themes that locative media projects frequently have sought to address, yet Dourish and Bell totally ignore this field. We therefore suggest supplementing their proposed ubicomp agenda for the next decades with insights from locative media.

Our contention is that locative media already questions the idea that computing necessarily can or should solve the messiness of everyday life. Instead, locative media's emphasis on story-telling exposes how reveryday life is constituted through people's ongoing engagement with their environment, rather than simplifying it to neat pre-defined categories. With its roots in reflexive artistic practice as opposed to computer research, the ubiquitous computing medium and its mediating processes are scrutinized by locative media in selfsame terms as proposed by that Dourish and Bell: legibility, literacy and legitimacy.

Digital technologies can render the everyday world collectively legible in two ways. Dourish and Bell note "panoptic legibility« (ibid.: 194). involves centralist modern planning. It is a view from above that seeks to eliminate differences in favor of a coherent ordering. Local legibility, by contrast, looks at the heterogeneity of objects and actions. It reflects how people in practice engage with the world and emphasizes individual differences. This relates to ideas of spatial practice developed out of strains of 1968 thought we have called postmodern geography, and to the work of Kevin Lynch discussed above. Dourish and Bell talk about "making the invisible visible " in location-based systems, social networking and data mining (ibid.: 195), and they critique sensing technologies as ordering the world rather than describing it (ibid.: 195). While Dourish and Bell call for ubicomp research to engage more consciously with these issues in the future, already for a decade locative practices have designed, performed and discussed the new ssituations made possible by ubicomp. In contrast to ubicomp researchers, who must make incremental advancements toward a projected realistic and singular future, artists, designers, and even activists who produce locative media have been concerned with exploring alternative multiple futures.

With literacy, Dourish and Bell draw attention to the ways in which ubicomp represents objects and activities in everyday life. Again unsurprisingly from the viewpoint of locative media, they turn to cartography and mapping. Here too they distinguish between top-down and bottom-up practices, or what in ethnography is known as an setic view from the outside versus an semice insiders view. In contrast to the standardizing Mercator projection, the familiar world atlas centered on the West, people's soccasion maps` or `mud maps con- 
sist of just the situated information particular to that context. When people draw out directions to someone, they narrate a journey instead of representing space as a homogeneous Cartesian container (ibid.: 197). Cultural knowledge here is figured as performative rather than representational. Locative media draws on at least a century of semic $<$ concepts and theory from human geography and (urban) ethnography: from Baudelaire and Benjamin's flaneur, or the Situationist' concept of psychogeography, to the idea of 'geosophical folkmapping as a way to bring out local spatial knowledge (Wright 1947).

With a focus on legitimacy Dourish and Bell aim to show that on-the-ground forms of senvironmental knowing are not always compatible with the dominant technical rationality that underlies the modern worldview. Data-analysis and smanagement by the numbers, as for instance found in neoclassical economics and macro-economic modeling, not only describe the world but quickly come to act as prescriptions that organize the world. Struggles for the legitimacy of alternative worldviews may arise around issues like land use (Dourish/ Bell 2011: 198f.):

"As scientific and computational accounts of the social and natural world are the basis of industrial and governmental practice, they inevitably come into conflict with the alternative epistemologies that they displace. $\ltimes$

Here, with an odd twist, the substitution issue resurfaces in the question whether alternative forms of spatial knowledge are indeed displaced by computation, or linger on in the background (and therefore can be exposed by using media technologies). In their effort to connect the seemingly remote disciplines of ubicomp and ethnography, Dourish and Bell overlook the proximate field of locative media that frequently seeks to bring to light these salternative epistemologies«. For example, NomadicMILK is an artistic locative media project that juxtaposes two very different dairy economies in Nigeria: the rationalized and global distribution chain of Peak Milk (a Friesland Foods subsidiary), and a traditional nomadic dairy economy of Fulani herdsmen. ${ }^{4}$ Polak's side-by-side portrayal of these two milk routes suggests that both can co-exist in relative harmony (although conflicts do arise). Another example of how alternative spatial epistemologies are teased out through locative media practices is the Community Mapping project initiated by Mapping for Change, which aims to be

4 Esther Polak and team 2010, http://www.nomadicmilk.net. a repository of community knowledge on local resources, facilities and activities. ${ }^{5}$

In order not to drown in a wealth of examples to show how locative media practices can inform ubicomp along these three lines, let us consider - as a pars pro toto - the oft-cited project Bio Mapping by Christian Nold (2009). ${ }^{6}$ In Bio Mapping, participants went out for a walk in their neighborhood while wearing a custom device that measured their galvanic skin response, an indicator of emotional arousal, and a GPS device that logged their movements. Upon their return, an semotional map was compiled with three-dimensional spikes at points were people felt aroused (like busy junctions). Over a number of years Nold reworked this project into a workshop format in which the maps generated would become the basis for a conversation with and amongst community members about their neighborhoods.

The project shows that scontext is a far more intricate notion than simply a matter of adding computer-generated time and location stamps to digital information, which can subsequently be rreadc. Bio Mapping makes urban space legible as a combination of subjective intimate experiences and objective technological infrastructures and measurements (ibid.). The project exposes a normally hidden view of urban space in terms of emotions. In fact, semotion designates a range of different sensations and affects that only come to light when actors reflect and speak for themselves. Nold recounts (ibid.: 5):

"While I would see just a fairly random spiky trail, they [the participants] saw an intimate document of their journey, and recounted events which encompassed the full breadth of life: precarious traffic crossings, encounters with friends, meeting people they fancied, or the nervousness of walking past the house of an ex-partner.*

The project shows that each time people traverse the city, they write urban space with their own emotional experiences in addition to merely reading it. Following others, we suggest to supplement Dourish and Bell's notion of legibility with 'writabilitys, to emphasize how ubicomp not just makes space readable

5 http://www.communitymaps.org.uk.

6 http://biomapping.net. 
but helps to produce space by allowing people to inscribe it with their own affects. ${ }^{7}$

Further, from this project we see that people are not thoughtless end-users of urban spaces but, crucially, reflect on their own actions and their environment. Literacy is not some property or quality of people but a "process of scaling-up and seeking connections « (ibid.: 7). When participants during the workshops started to talk among each other about their personal walks, discussions would arise about the lack of public space and its causes. Locative media - itself a network of, among others, the various technologies used, the participants, the artist, and the workshop setting - thus comes to act as a mediator instead of a mere intermediary (Latour 2005: 37-40). That is, the locative media representations did not merely reflect the participants' spatial experiences but induced a change (a sdislocations) in how they act in their environment. In Latourian terms, it allowed them to reassemble their relation to the city and fellow urbanites. We therefore suggest that the notion of literacy is not so much about how ubicomp represents actions and objects but more about its potential for collective action, like in this case discussing neighborhood issues and creating change. Departing from the quantified logics of measuring bodily variables, geopositioning and data-visualization, people presented their own forms of local knowledge to each other during the workshop sessions. As personal experiences were scaled-up to a communal level, locative media acted as conversation pieces that induced people to become political in the sense of forming a collective around a communally shared issue. The issue of legitimacy then does not necessarily mean that salternative spatial epistemologies` are passive victims of the brutal logics of quantified calculation. This dominant logic inherent in computation does not substitute alternative worldviews, as Dourish and Bell seem to imply, but instead injects them with new force. Bio Mapping's hybridity shows how a qualitative variety of salternative worldviews can exist side by side with quantitative calculations, and indeed are mutually constitutive as »qualculation« (Callon/Law 2003; Thrift 2008: 24, 90, 98).

7 We draw inspiration from Lawrence Lessig's term read/write cultures, which has been reused as read/write city by Kevin Slavin and Adam Greenfield to describe how wthe city's users are no longer bound to experience passively the territory through which they move but have been empowered to inscribe their subjectivities in the city itself... that those subjectivities can be anchored in place and responded to by those who come after (Greenfield/Shepard 2007: 13).
All this is highly consequential to the idea of ubicomp as simply adding convenience to people's lives in a range of everyday situations by calmly residing in the background. Our discussion of Bio Mapping shows - in line with Dourish and Bell's aims - that pervasive technologies, as well as the situations created around them are active agents of change in people's relationship with the world and each other. In addition, we have tried to add further insights and refinements to their notions of legibility, literacy, and legitimacy. Surely there is still a considerable gap between this artistic locative media project aimed at debate and actually instigating action. We turn to this point in the final section.

\section{EXECUTABLE URBANISMS}

As human geography has long claimed, space is not an empty container, but rather the dialectical outcome of social forces (Lefebvre 1991). Dourish and Bell contend that ubicomp pays insufficient attention to how technologies act as sites for everyday social and cultural production and meaning, and how space in turn is framed by these scultural logics $\varsigma$. The fundamental relationality they argue for is built into many locative media projects to a large degree, as the artists engage with the participants and let them speak for themselves. Locative media is not a technological narrative created for other people as much as a means by which people tell stories about themselves. It is not the "view from nowhere " of traditional cartography but presents radical on-the-ground views of senvironmental knowing (Dourish/Bell 2011: 199f.), and is therefore political (as in the spolitical rather than spolitics ). The cultural sensitivity Dourish and Bell call for is already evident in locative media practice. In contrast to ubicomp's largely western, even Anglo-Saxon, research bias (ibid.: 15, 21), locative media have for the past decade been developed by media makers and artists worldwide.

Once the privileged domain of architects and planners, emerging manifestations of ubicomp enable people to quite literally produce urban space. For example, sparticipatory mapping s is a design process that turns urban planning into a public matter (Vajjhala 2005, Vajjhala/Walker 2009; Gordon et al. 2011). As we have seen in Dourish and Bell's critique, present-day ubicomp tends to conceive of space in relatively static and uncritical terms. While the practices of architecture and planning have their own traditions of critique, which have in turn informed locative practice, in the words of Dourish and Bell, ubicomp has 
tended to minimize the role of theory. They propose that ubicomp researchers use theory in order to scrutinize and enrich those concepts (like space, context, everyday life, and culture) that they have taken for granted. A turn to ethnographic theory foregrounds that (Dourish/Bell 2011: 130f.):

the encounter with space is framed by cultural logics, or a series of collective understandings through which space, spaces, and their representations take on particular kinds of meaning. These logics are themselves social products; they arise out of our actions and interactions as we move around in and make sense of the world."

Drawing theoretical insights from ethnography, Dourish and Bell illustrate how concepts of location can vary dramatically across cultures. Likewise, Latour (1993) advocates we learn from inon-modern cultures, who acknowledge the agency in non-human things, in order to avoid producing the smonstrous hybrids of modern science. In terms of ubicomp learning about a non-modern mode of spatial practice, Dourish and Bell for instance suggest the model of indigenous Australian culture, whereby the landscape is both inscribed and performed within an animistic belief system. In this tradition narratives are conceived of as emerging from and giving shape to the land. ${ }^{8}$

We have seen how discourses from cultural geography and anthropology have informed locative practice over the past decade. A major challenge in our eyes is to design technologies and projects that strengthen a sense of collective ownership over the environment, that enable people to mould and shape the city to their liking, and (re)connect to their fellow urbanites. Now that much of the technology explored by locative media has become sblack-boxed into high and even mid-end mobile devices, the so-called "read/write city« of visualization and annotation is commonplace (Greenfield/Shepard 2007: 13). To conclude, we want to push the UNIX analogy further by proposing the idea that locative media suggests a future of multiple "executable urbanisms $\ll, 9$ A first step in this direction may be exemplified by projects that allow people to report

8 This concept inspired GPSter, an early digital annotation project exhibited as Song lines at the 2003 IMPAKT festival Utrecht, which enabled people to swriter their own space through connecting a GPS-enabled wireless device to a database of swaypoints thereby enabling contextual variables to represent space in terms of an accretion of social traces (for more on the project see: Dietz 2006).

9 The authors wish to thank Emilie Randoe for her suggestion to extend the »read/ write \& metaphor. small problems in their neighborhood by locating and tagging them on a map, via a web interface or mobile application. ${ }^{10}$ Through engaging citizens as codesigners of space, projects are iterating towards a model for the executable city model in which different local stakeholders are assembled to map and even collectively design their environment via a DIY locative tool-set. ${ }^{11}$ Executable urbanisms are based on the improvised uses of the locative technologies embedded in the mess of global cosmopolitics as opposed to the gleaming singular future envisioned by ubiquitous computing.

\section{BIBLIOGRAPHY}

Agnew, John A. (1987): Place and Politics: The Geographical Mediation of State and Society, Boston.

Aurigi, Alessandro/De Cindio, Fiorella (2008): Augmented Urban Spaces: Articulating the Physical and Electronic City, Aldershot.

Barbrook, Richard (2007): Imaginary Futures: From Thinking Machines to the Global Village, London.

Batty, Michael (1995): »The Computable City«, in: Robin Wyatt/Hemayet Hossein (Eds.), Proceedings of Fourth International Conference on Computers in Urban Planning and Urban Management, http://www.acturban.org/ biennial/doc_planners/computable_city.htm, 24.08.2009.

10 An example is Fixmystreet (http://www.fixmystreet.com). While this is a way to engage people with their living environment, reporters are still dependent on a local authority to actually solve the problem instead of being allowed to fix it themselves. Moreover, the problems addressed by Fixmystreet are relatively easy targets: graffiti, litter, a broken lamp.

11 As an example of the emergence of this executable city in terms of mapping consider the use of the Pachube platform provided alternatives to the official accounts of the disaster at Fukushima Daichi nuclear reactor in Japan, in which citizen scientists set up do-it-yourself sensors networks to crowd-source radiation readings (Kera 2011). And in terms of executable urban design, consider Face Your World (http://www. faceyourworld.nl/slotervaart.php) by Dutch media-artist Jeanne van Heeswijk in collaboration with architect Dennis Kaspori, which set up a temporary project space in an Amsterdam neighborhood, and used a self-developed multimedia environment to gather, visualize, and discuss ideas generated by local citizens. 
Bell, Genevieve/Dourish, Paul (2006): "Yesterday's Tomorrows: Notes on Ubiquitous Computing's Dominant Vision«, in: Personal and Ubiquitous Computing, 11(2), 133-143.

Benjamin, Walter (2008): »The Work of Art in the Age of Its Technological Reproducibility", in: The Work of Art in the Age of Its Technological Reproducibility, and Other Writings on Media, edited by Michael W. Jennings et al., Cambridge, MA, 19-55.

Callon, Michael/Law, John (2003): "On Qualculation, Agency and Otherness«, the Centre for Science Studies, Lancaster University, http://www.lancs.ac. uk/fass/sociology/papers/callon-law-qualculation-agency-otherness.pdf, 10.11.2008.

Castells, Manuel/Hall, Peter (1994): Technopoles of the World: The Making of Twenty-First-Century Industrial Complexes, London.

Cobarrubias, Sebastian/Pickles, John (2009): »Spacing Movements: The Turn to Cartographies and Mapping Practices in Contemporary Social Movements«, in: Barney Warf/Santa Arias (Eds.), The Spatial Turn: Interdisciplinary Perspectives, Abingdon, 36-58.

Crang, Mike/Graham, Stephen (2007): "Sentient Cities: Ambient Intelligence and the Politics of Urban Space«, in: Information, Communication \& Society, $10(6), 789-817$.

Davis, Mike (1992): City of Quartz: Excavating the Future in Los Angeles, London.

De Lange, Michiel (2010): Moving Circles: Mobile Media and Playful Identities, unpublished $\mathrm{PhD}$ dissertation, Erasmus University Rotterdam.

De Lange, Michiel/De Waal, Martijn (2009): »How Can Architects Relate to Digital Media?« http://martijnsdepot.com/mobilecity/wp-content/uploads/ 091206_report_BNA-dag1.pdf, 09.08.2010.

Dear, Michael (2000): The Postmodern Urban Condition, Oxford.

Debord, Guy (1955): »Introduction to a Critique of Urban Geography«. in: Les Lèvres Nues 6, translation online, http://library.nothingness.org/articles/ SI/en/display/2, 08.06.2011.

Deleuze, Gilles (1988): Foucault, London.

Dietz Steve (2006): "Mapping the Urban Homunculus«, in: Janet Abrahams/ Peter Hall (Eds.), Else/Where: Mapping: New Cartographies of Networks and Territories, Minneapolis.

Dimendberg, Edward (1998): "Henri Lefebvre on Abstract Space«, in: Andrew Light/Jonathan M. Smith (Eds.), The Production of Public Space (Philosophy and Geography), Lanham, MD, 17-47.
Dourish, Paul/Bell, Genevieve (2011): Divining a Digital Future: Mess and My. thology in Ubiquitous Computing, Cambridge, MA.

Downey, John/McGuigan, Jim (Eds.) (1999): Technocities, London.

Foth, Marcus (2009): Handbook of Research on Urban Informatics: The Practice and Promise of the Real-Time City, Hershey, PA.

Goldsmith, Jack/Wu, Tim (2006): Who Controls the Internet?: Illusions of a Borderless World, Oxford.

Gordon, Eric et al. (2011): »Immersive Planning: A Conceptual Model for Designing Public Participation with New Technologies«, in: Environment and Planning B: Planning and Design, 38(3), 505-519.

Gottdiener, Mark (1994): The Social Production of Urban Space, Austin.

Graham, Stephen (Ed.) (2004): The Cybercities Reader, London/New York.

Greenfield, Adam/Shepard, Mark (2007): „Urban Computing and Its Discontents«, in: Omar Khan et al. (Eds.), Situated Technologies Pamphlet Series, 1, http://www.situatedtechnologies.net, 06.10.2011.

Hampton, Keith N./Wellman, Barry (1999): »Netville Online and Offline: Observing and Surveying a Wired Suburb«, in: American Behavioral Scientist, 43(3), 475-492.

Hayles, Katherine/Gannon, Todd (2012): "Virtual Architecture, Actual Media«, in: C. Greig Crysler et al. (Eds.), The Sage Handbook of Architectural Theory, 6(3), Thousand Oaks, 484-500.

Holmes, Brian (2004): "Imaginary Maps, Global Solidarities«, http://www. 16beavergroup.org/mtarchive/archives/000868.php, 10.12.2007.

Ito, Mizuko et al. (Eds.) (2005): Personal, Portable, Pedestrian: Mobile Phones in Japanese Life, Cambridge, MA

Jameson, Frederic (1991): Postmodernism, or, the Cultural Logic of Late Capitalism, Durham.

Jay, Martin (1994): Downcast Eyes: the Denigration of Vision in Twentiethcentury French Thought, Berkeley.

Kera, Denisa (2011): „Design Probes as Social Innovation: Participatory Monitoring of Radiation After Fukushima«, in: APSTSN, July 19-21, 2011, Shenyang, China.

Kuitenbrouwer, Klaas (2006): »RFID and Agency: The Cultural and Social Possibilities of RFID «, in: Open, 11, 50-59.

Latour, Bruno (1993): We Have Never Been Modern, Harvard.

Latour, Bruno (2005): Reassembling the Social: An Introduction to ActorNetwork-Theory, Oxford. 
Lefebvre, Henri (1991 [1974]): The Production of Space, Oxford.

Lukacs, Georg (1967): History and Class Consciousness: Studies in Marxist Dialec tics, London.

Lynch, Kevin (1960): The Image of the City, Cambridge, MA.

McCullough, Malcolm (2004): Digital Ground: Architecture, Pervasive Computing, and Environmental Knowing, Cambridge, MA.

McLuhan, Marshall. (1994): Understanding Media: the Extensions of Man, Cambridge, MA.

Meyrowitz, Joshua (1985): No Sense of Place: The Impact of Electronic Media on Social Behavior, New York/Oxford.

Miller, Daniel/Slater, Don (2000): The Internet: an Ethnographic Approach, 0xford.

Mitchell, William J. (1995): City of Bits: Space, Place, and the Infobahn, Cambridge, MA.

Mitew, Teodor (2008): »Repopulating the Map: why Subjects and Things are Never Alone«, in: The Fibreculture Journal, 13, http://www.thirteen. fibreculturejournal.org/fcj-089-repopulating-the-map-why-subjects-andthings-are-never-alone, 16.12.2009.

Moran, Thomas/Dourish, Paul (2001): "Introduction to The Special Issue on Context-Aware Computing«, in: Human-Computer Interaction, 16 (2-3), 87 95.

Nold, Christian (Ed.) (2009): Emotional Cartography: Technologies of the Self, http://emotionalcartography.net, 22.12.2010.

November, Valérie et al. (2010): »Entering a Risky Territory: Space in the Age of Digital Navigation«, in: Environment and Planning D: Society and Space, 28, 581-599.

Nyíri, Kristóf (Ed.) (2005): A Sense of Place: The Global and the Local in Mobile Communication, Vienna

Rogers, Richard (2009): »The End of the Virtual - Digital Methods«, http:// www.govcom.org/rogers_paris_medialab.pdf, 01.02.2012.

Shepard, Mark (Ed.) (2011): Sentient City: Ubiquitous Computing, Architecture, and the Future of Urban Space, Cambridge, MA.

Smith, Neil (1998): »Anotomies of Space and Nature in Henry Lefebvre's The Production of Space«, in: Andrew Light/Jonathan M. Smith (Eds.), The Production of Public Space (Philosophy and Geography), Lanham, MD, 49-67.

Sorkin, Michael (1992): Variations on a Theme Park: The New American City and the End of Public Space, New York.
Tafuri, Manfredo (1979): Architecture and Utopia: Design and Capitalist Development, Cambridge, MA.

Thielmann, Tristan (2010): „Locative Media and Mediated Localities: An Introduction to Media Geography«, in: Aether, 5a, 1-17, http://130.166.124.2/ aether/pdf/volume_05a/introduction.pdf, 10.12.2010.

Thrift, Nigel (2008): Non-Representational Theory: Space, Politics, Affect, Abingdon.

Townsend, Anthony (2000): "Life in the Real-Time City: Mobile Telephones and Urban Metabolism«, in: Journal of Urban Technology, 7(2), 85-104.

Tuters Marc (2004): $n$ The Locative Commons: Situating Location-Based Media in Urban Public Space«, in: Futuresonic 2004, http://www.futuresonic. com/futuresonic/pdf/Locative_Commons.pdf, 10.06.2012.

Tuters Marc/Smite Rasa (Eds.) (2004): Transcultural Mapping Reader, http://web.archive.org/web/20060520071802/http://locative.net/ tcmreader/, 10.06.2012.

Tuters, Marc/Varnelis, Kazys (2006): "Beyond Locative Media«, http:// networkedpublics.org/locative_media/beyond_locative_media, 20.02.2008.

Vajjhala, Shalini P. (2005): »Integrating GIS and Participatory Mapping in Community Development Planning«, in: ESRI User Conference, San Diego, July 25-29, 2005, http://proceedings.esri.com/library/userconf/proc05/ papers/pap1622.pdf, 25.08.2011.

Vajjhala, Shalini P./Walker, Wendy M. (2009): »Roads to Participatory Planning: Integrating Cognitive Mapping and GIS for Transport Prioritization in Rural Lesotho«, in: Resources for the Future RFF DP 09-26, http://www. rff.org/RFF/Documents/RFF-DP-09-26.pdf, 25.08.2011.

Virilio, Paul (1991): The Lost Dimension, New York.

Virilio, Paul (1997): Open Sky, London.

Wilson, Louise (1994): „Cyberwar, God And Television: Interview with Paul Virilio«, in: Ctheory, ed. Arthur and Marilouise Kroker, a020, 12.01.1994 http://www.ctheory.net/printer.aspx?id=62, 10.12.2010.

Wright, John K. (1947): "Terrae Incognitae: The Place of Imagination in Geography «, in: Annals of the Association of American Geographers, 37, 1-15.

Zukin, Sharon (1993): Landscapes of Power: From Detroit to Disney World, Berkeley. 